\title{
Geothermic activity and seismotectonics in the altitude of the Tibetan plateau *
}

\author{
Jiren $\mathrm{Xu}^{*}$ and Zhixin Zhao \\ Institute of Geology, Chinese Academy of Geological Sciences, Beijing 100037, China
}

\begin{abstract}
In the present analysis on the relationships among the depth of lithosphere brittle fracture, seismotectonics and geothermal anomalous active in Tibetan plateau were investigated using the seismic dada from ISC and Chinese seismic net and geothermal data. The results suggest that the region of anomalously geothermal activity almost coincides with that of the normal faulting type earthquake. The geothermal anomaly activity region coincides spatially with that of the events deeper than $60 \mathrm{~km}$ as well as. The normal faulting earthquakes may be mainly tectonic activity regimes until $110 \mathrm{~km}$ deep in the thermal anomaly region. The strike directions of events are likely the N-S direction, coinciding with the strike of the thermal anomaly active belts. The earthquakes align along the normal faults and faulted-depression zone with the N-S direction. The thermal anomaly activity also distributes along the faulted-depression zone. Many events deeper than $60 \mathrm{~km}$ exist in the anomalously geothermal activity region in the plateau. Events extend to bottom of the lithosphere of $110 \mathrm{~km}$ from the surface, like columnar seismic crowd. The lithosphere extends along the E-W direction due to the E-W extensional stress in the central and southern Tibetan plateau, altitude of the plateau. The tensional stress in the E-W results in the lithosphere fractures and the normal faults striking N-S direction, grabens and faulted-depression zones. Thermal material from the asthenosphere wells upward to the surface along deep seismic fractures and faults through the thick crust. The anomalously thermal activities are attributable to the upwelling thermal material from the mantle in the altitude of Tibetan plateau.
\end{abstract}

Key words: Tibetan plateau; normal faulting type earthquake; geothermic activity; middle and deep earthquakes; seismotectonics

CLC number: P314.2, P315.2 Document code: A

\section{Introduction}

The Indian plate collides with and subducts underneath the Eurasian plate along the southern edge of the Himalayas. The compressive tectonic force due to the collision along the Himalayas between the Indian and Eurasian plates results in orogeny motions in the Himalayas, Tibetan plateau, and Altyn and Qilian mountains (Molnar et al, 1993). Such violent crustal movements and strong earthquakes extend to the Tianshan Mountains (Qin et al, 2002; Xu, 2001). The compressive tectonic force affects crustal motions in the west of China and as far as Mongolia (Robert et al, 1997; Brown et al, 2002). Such motion and deformation make the Tibetan plateau and its surrounding areas one of the most active regions in terms of tectonics and seismicity in the world (Wang and $\mathrm{Xu}, 2003$ ). The synchronous temporal variations of the seismic activities on the Tibetan plateau and

\footnotetext{
* Received 12 June 2009; accepted in revised form 20 October 2009; published 10 December 2009.

^Corresponding author.e-mail: xujiren1125@yahoo.com.cn
}

its vicinities are related to the compressive collision between the Indian and Eurasian plates (Zhao et al, 1990). Many papers have reported significant findings in the fields of tectonics and seismicity in this region (Zhang, 2000; Fu et al, 2000). Besides the compressive tectonic motions, some extensional tectonic motions have been reported on the Tibetan plateau. The normal faulting type motions on the Tibetan plateau is attributable to the gravitational collapse of the high plateau $(\mathrm{Xu}$ et al, 1988). Extensional crevices and grabens were also detected on the Tibetan plateau.

The geothermal phenomena occur acutely in and around the southern and central region of the Tibetan plateau beside the intensively seismic activity. The high heat flow values at the surface vary greatly with the locations, the heat exchange ways are also variable in the area. The conduction type heat flow and conduction-convection one interlace even in small area. Various hypotheses have been introduced to explain the high geothermal and heat flow anomalies in the area, e.g., the conduction type of heat flow in depth may be attributive 
to the magma intruding activities in the crust. It may be related to the hot structure similar to that in the southern region in the plateau. The high heat flow anomaly is attributable the convection of heat-water among the fault tunnels like that in the Himalayan mountains (Han, 1990). The geothermal process may be caused by the tectonic deformations (Housemen and Mckenzic, 1981). We will investigate further the relation between geothermal anomalies and the seismotectonics in the altitude regions of the Tibetan plateau in the present analysis. The relationship between the different earthquake fault types and the anomalously thermal activity is going to be investigated in the present analysis as well as. The data from the seismic networks of Chinese Seismic Bureau, Harvard university and ISC etc. are used in the investigation (Xu, 1994, Xu et al, 2008).

\section{Geothermal activity}

The rich geothermal resources exist in the Tibetan plateau. Figure 1 shows geological tectonic and geothermal activities in the region. The geothermal phenomena occur intensively in the central and southern regions of the plateau especially (Han, 1990). It can be seen from Figure 1 that the geothermal anomaly activities almost concentrated in the Lhaze-Gangdise block that is bounded by the Yaluzangbu river and the Bangong-Nong river on the southern and northern sides extending along E-W direction, respectively. The early major compressive or compressive-shear faults with large scale along the E-W direction lie at the northern and southern boundary of the geothermal anomaly area. There are many active faults, the normal ones along the $\mathrm{N}-\mathrm{S}$ direction in the area. Moreover a number of faulted-depression zones with near N-S or NNE strike direction, appear in the block as shown in Figure 1. Many boiling spring, geyser and boiling fountain, thermal and hot springs distribute in the plateau. The high heat flow anomaly phenomena, however, appear evidently along the splitting valleys likely the N-S direction. It is interested that many hydrothermal activities gather along the above extensional faulted depression zones. Such geothermal activities character typically the thermal structures in the altitude of the Tibetan plateau.

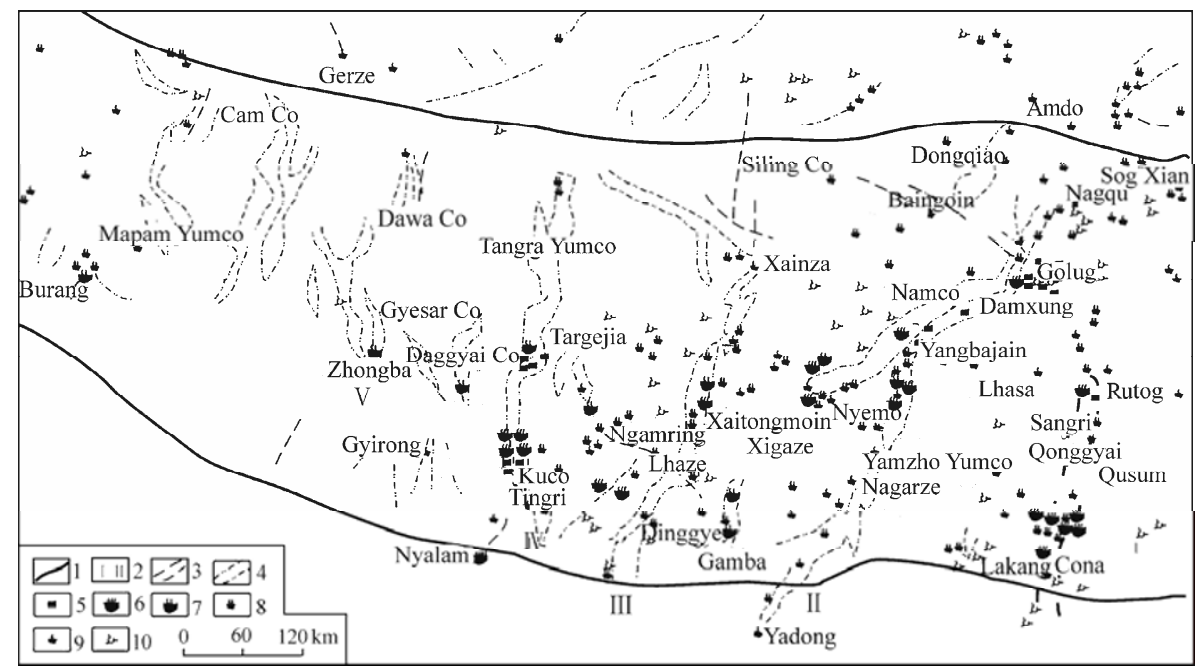

Figure 1 Distribution of geothermal manifestations and relative tectonic structure in the central and southern Tibetan plateau, altitude of the plateau (after Han, 1990). [about $80^{\circ} \mathrm{E}-93^{\circ} \mathrm{E}, 27^{\circ} \mathrm{N}-33^{\circ} \mathrm{N}$; e.g., Pulan $\left(81.12^{\circ} \mathrm{E}\right.$, $\left.30.2^{\circ} \mathrm{N}\right)$, Yadong $\left(88.58^{\circ} \mathrm{E}, 27.31^{\circ} \mathrm{N}\right)$, Naqu $\left(93.56^{\circ} \mathrm{E}, 31.31^{\circ} \mathrm{N}\right)$, Ando $\left.\left(91.41^{\circ} \mathrm{E}, 32.17^{\circ} \mathrm{N},\right)\right]$. 1 . Early major compressive or compressive-shear fault; 2 . The number of active tectonic zone; 3 . Boundary fault in active tectonic zone; 4. Faulted-depression zone in active tectonic zone; 5. Site of sampling; 6. Boiling spring; 7. Hydrothermal explosion, geyser and boiling fountain; 8. Thermal spring; 9. Hot spring; 10. Untested hydrothermal area.

The linear temperature gradient is as high as $46.5^{\circ} \mathrm{C} / \mathrm{km}$ at the depth between 1030 and $1410 \mathrm{~m}$ in the Yangbajain area. The heat flow density is about $108 \mathrm{~mW} / \mathrm{m}^{2}$ at the surface here (Shen et al, 1989). The above geothermal parameters in the Tibetan plateau are much greater than the average values in other continental region of China. The hydrothermal explosion, geyser and boiling fountain with high temperature of $93{ }^{\circ} \mathrm{C}$ have been surveyed in the plateau (Wei et al, 1981). The hot liquid with high temperature of $329{ }^{\circ} \mathrm{C}$ is also sur- 
veyed at $2 \mathrm{~km}$ deep in the area recently. The rare high heat flow value of $364 \mathrm{~mW} / \mathrm{m}^{2}$ is observed in the area (Han, 1990).

\section{Seismicity}

Seismic activity and source mechanism solutions can character the tectonic movements of lithosphere. Moreover, earthquakes with the middle and deep depth character the structure and mutual action of the crust-mantle (Xu and Kono, 2002; Xu et al, 2003). The characteristics of seismicity and stress field in the central part are different from those in the surroundings of the plate (Zhao et al, 1988). Earthquakes greater than $M 7.0$ occurred almost in the surroundings, e.g., recently, Wenchuna $M_{\mathrm{S}} 8$ event in the eastern edge, both of the M7.9 events in 1997 and 2001 occurred along the Kunlunshan fault that is the north edge of the plate. Events with hypocenter deeper than $100 \mathrm{~km}$ occurred in the eastern and western ends of the Himalayan collision zone, Myanmar region and the Hindukush-Pamir, the hypocenter depths are $330 \mathrm{~km}$ and $180 \mathrm{~km}$, respectively. The seismicity in the inner of the plate is quieter than that in the surroundings. The seismicity in the southern and central regions of the plateau is more active than averaged level of that in the inner region of the plateau. Majority of the hypocenters of events in the inner plate are less than $33 \mathrm{~km}$. The 36 events with middle magnitude equal to and greater than M5.0 occurred in the southern and central regions of the plateau after 1972. The largest one of them is the 30, July 1992 M6.3 event $\left(29^{\circ} 37^{\prime} \mathrm{N}, 90^{\circ} 10^{\prime} \mathrm{E}\right)$.

Figure 2 shows events of the hypocenters equal to or greater than $60 \mathrm{~km}$ during the period between 1964-2000 in and around the Tibetan plateau based on the data base from USGS. It is the reason because the database provides more events with hypocenter depth. A lot of events with middle and deep depth occurred in the altitude of the plateau, besides the collision- subduction zones, the western end of the Himalayan zone, the Hindukush-Pamir and in the eastern end of Himalayas, Myanmar region. Depths of the events range between 60 and $110 \mathrm{~km}$. The region occurring the middle and deep events in the plateau in Figure 2 coincides well with the geothermal anomaly region in Figure 1. Such consistent spatial distribution implies that the thermal anomaly activity is probably related to the middle and deep seismic activity.

The 1065 events collected from catalogues of the
Chinese Seismological Bureau ( $M \geq 1.2$, 1972-2000), ISC $(M \geq 4,1964-1998)$ and USGS $(M \geq 4,1965-2000)$ are employed in the detailed seismicity analysis in and around the geothermal anomaly region. Figure 3 shows the example for seismicity around an anomalously geothermal activity region in the altitude of the plateau (in right diagram), and the profile of hypocenter distribution (in the left diagram), respectively. The seismicity reveals actively in and around the region, like a belt along the N-S direction. The belt distribution of epicenters coincides well that of the thermal activities as shown in Figure 1 . The two middle and strong events occurred during the period between 1972 and 2000 in the southern and central region of the plateau. A $M 6.8$ event occurred in the northwestern area of $A B$ zone in Figure 3 in the February 22, 1980, another M6.7event occurred south of that zone in the July 30, 1992.

Figure 3a shows the hypocenter profile of 230 events occurred in the geothermal anomaly region. Many middle and deep events extend to about $110 \mathrm{~km}$, besides the shallow events. For example, the September 14, 1976 M5.6 event $\left(89^{\circ} 36^{\prime} \mathrm{E}, 2^{\circ} 48^{\prime} \mathrm{N}\right)$ occurred at $107 \mathrm{~km}$ in the lithosphere. Events with middle and deep depths activate in the southern area where highly thermal anomaly is. However, events in the northern area are all crustal ones. Such hypocenter distribution implies that the seismicity is a tectonic motion related to the geothermal activity.

Analytical results based on the catalogue databases from USGS and ISC show that the events of middle and deep depth occur in the altitude region too as shown in Figure 2. The 187 events $(M \geq 4,1965-2000)$ from the USGS catalogues were employed in the seismicity analysis in the above region. The September 14, 1976 event $\left(M 5.5,29.81^{\circ} \mathrm{N}, 89.57^{\circ} \mathrm{E}\right)$ occurred at $82 \mathrm{~km}$ deep. The $M 4.3$ event $\left(89.37^{\circ} \mathrm{E}, 29.442^{\circ} \mathrm{N}\right)$ occurred at $113 \mathrm{~km}$ deep in March 7, 1992. Above data from the two independent catalog systems show events with the middle and deep depth activate beneath the anomaly area of high thermal flow. It suggests that analyses for seismicity of the events with the middle and deep depth are important for understanding of the thermal activity in the altitude parts of the plateau.

\section{Normal faulting type event and ex- tension tectonic motion}

The source mechanism solutions of earthquakes are important data for the analyses of lithospheric stress 


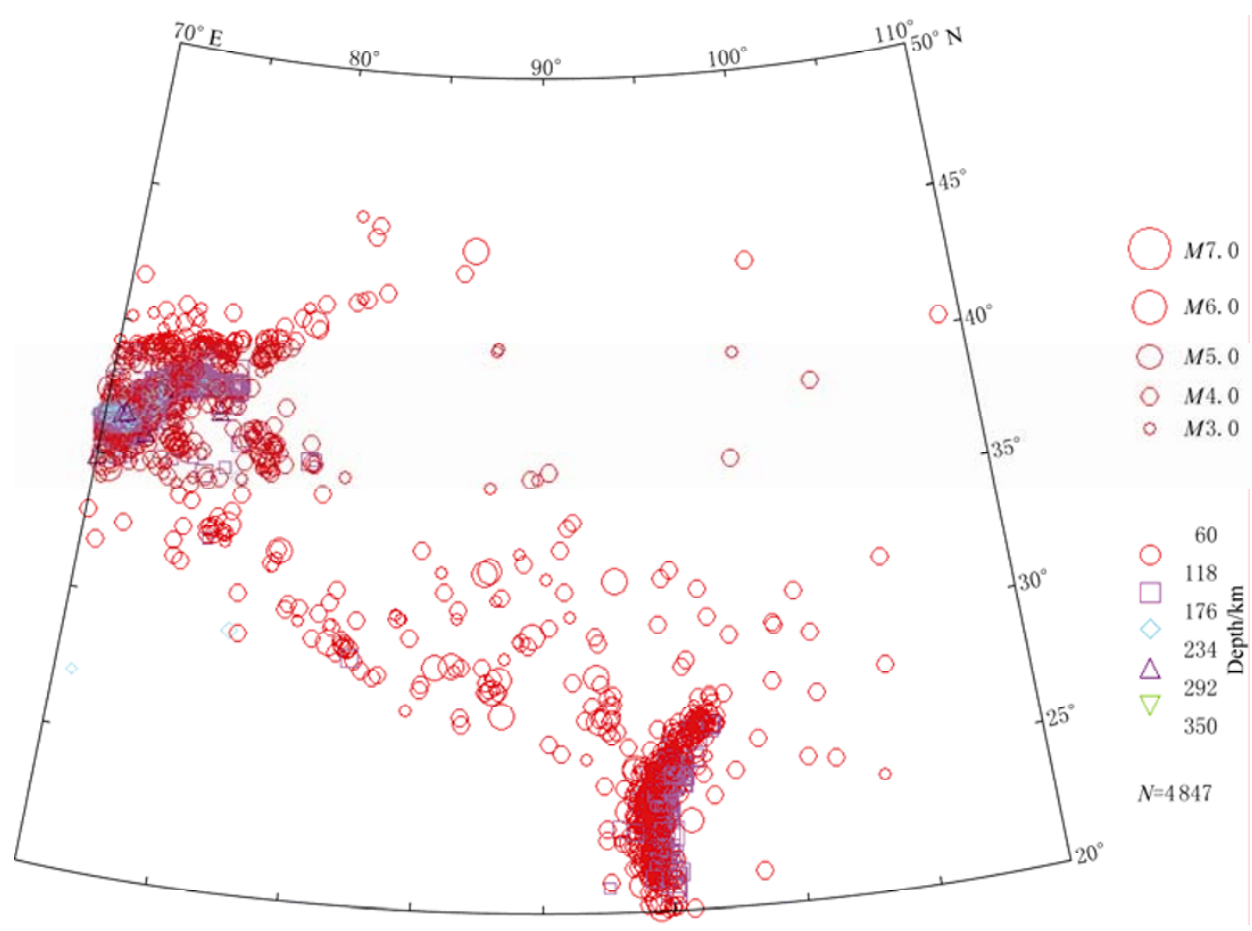

Figure 2 Distribution of middle and deep events in the Tibetan plateau (database after the USGS during 1964-2000, hypocenter depth $\geq 60 \mathrm{~km}$ ).

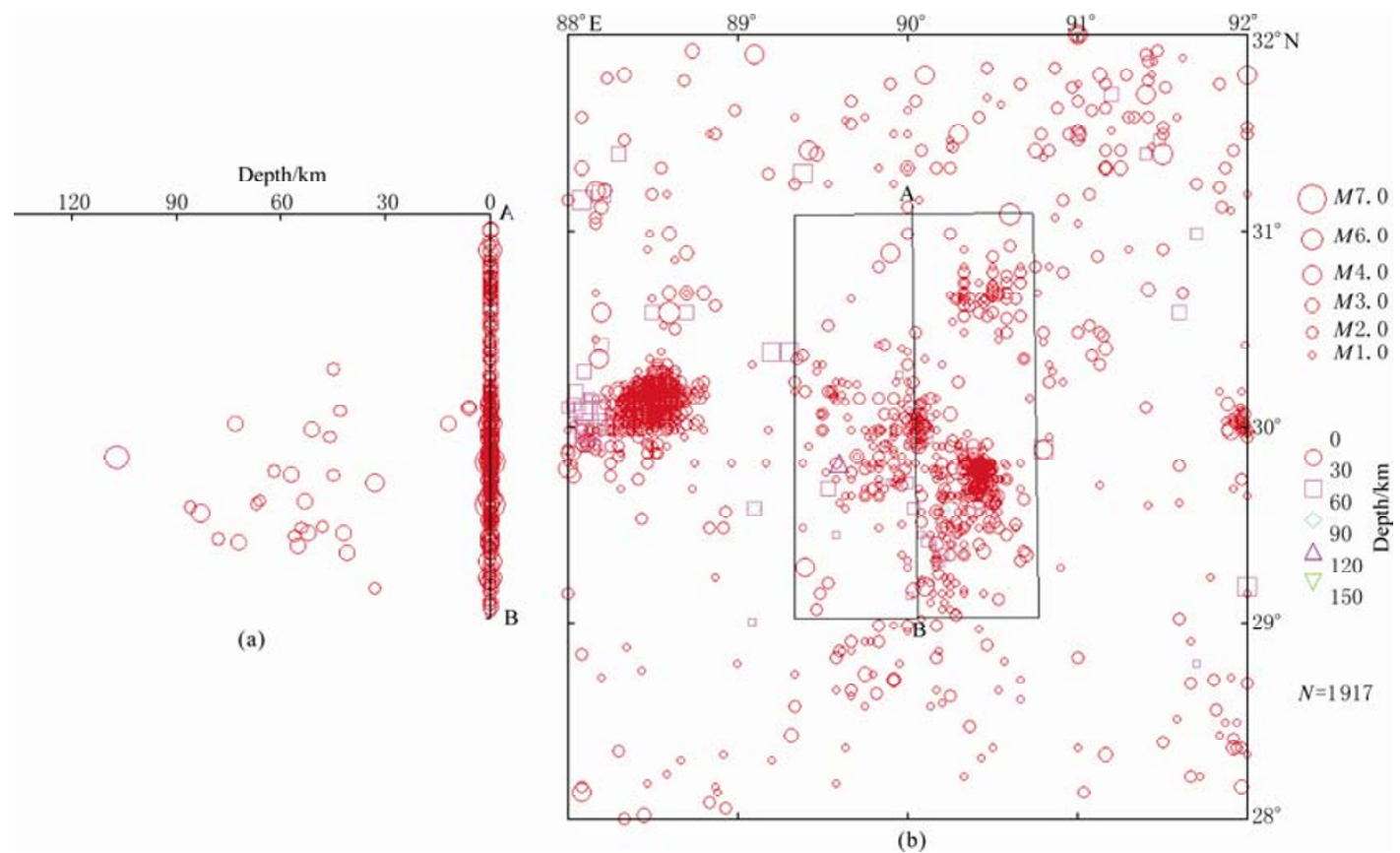

Figure 3 Seismicity in the high thermal anomaly region of the Tibetan plateau (b); Profile of the hypocenter distribution along line $A B$ (a).

field and the tectonic movement. The parameters of earthquake fault and source process obtained from seismic waveform reversion, e.g., spatial distribution of earthquake fault, area, and slip vector are important for study of dynamics of lithosphere motion. The 1559 source mechanism solutions of events $M \geq 4.5$ during the 


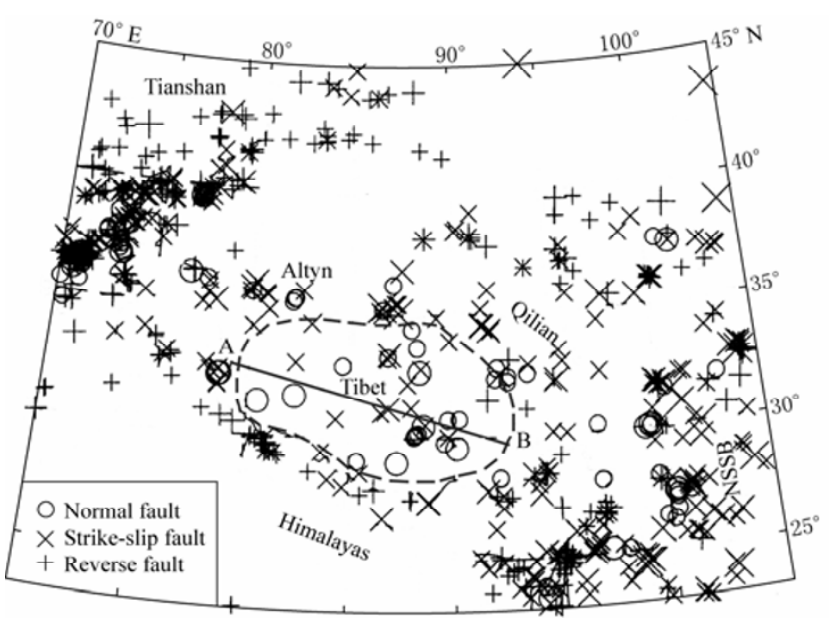

Figure 4 Distributions of normal, thrust and strike-slip faulting events that are divided depending on the plunge angles of compressive $P$ - and extensional $T$-axes.

period from 1931 to 2003 are used in the study of stress field and tectonic motion in and around the plateau. Some source mechanism solutions are determined using the data of ISC by the authors. Others are collected from other database and CMT results of USGS and the Harvard University. Hypocenters of all events are less than $110 \mathrm{~km}$.

Figure 4 shows the distributions of normal, thrust and strike-slip faulting events that are divided depending on the plunge angles of compressive $P$ - and extensional $T$-axes. It can be seen from Figure 4 that the compressive stress field due to collision between the Eurasian plate and Indian plate moving northward dominates the tectonic motions in the region from Himalayas to the Sayan mountain in Russian through the Tibetan plateau and Tianshan Mountains. The compressive stress with the NNE or NE direction causes many thrust and strike-slip faulting events in surrounding edges of the plateau.

Many normal faulting events concentrate obviously in the central and southern region in Tibetan plateau where the style of seismic activity formed by the normal faulting events differs from that by the thrust and strike-slip faulting events in the surrounding edges of the plateau. The region of normal faulting event ranges within the latitude $28.5^{\circ} \mathrm{N}-34.5^{\circ} \mathrm{N}$, and longitude $80^{\circ} \mathrm{E}-93^{\circ} \mathrm{E}$, encircled by a solid line $A B$ in Figure 4. The altitudes are mostly greater than $4500 \mathrm{~m}$ there. It is interesting that the region of the normal faulting type event in Figure 4 almost coincides that of geothermal anomaly activity in Figure 1. As example, Figure 5 shows the equal area projection diagrams of focal mechanism solutions (upper diagram) in the altitude of the plateau, central and southern region of the plateau and profiles of the $P_{-}, T$ - axes and equal area projection diagrams along line $A B$ (lower diagram). It can be seen that the $P$-axes are almost perpendicular to the surface. $T$-axes are almost parallel to the surface along line $A B$. The earthquake faults strike almost in the N-S direction. It suggests that an extensional stress field likely the E-W direction dominates the seismic activity and tectonic motion in the central and southern region of the plateau.

It can be seen by comparing results in Figures 1, 4 and 5 that the high geothermal anomaly area coincides in spatial well with extensional stress area in the altitude, the central and southern regions of the plateau. Small scale of normal faults and grabens striking in the N-S direction exit in the extensional stress region. A lot of normal faulting events concentrate in the altitude region in the plateau formed by the motions of compression and uplift.
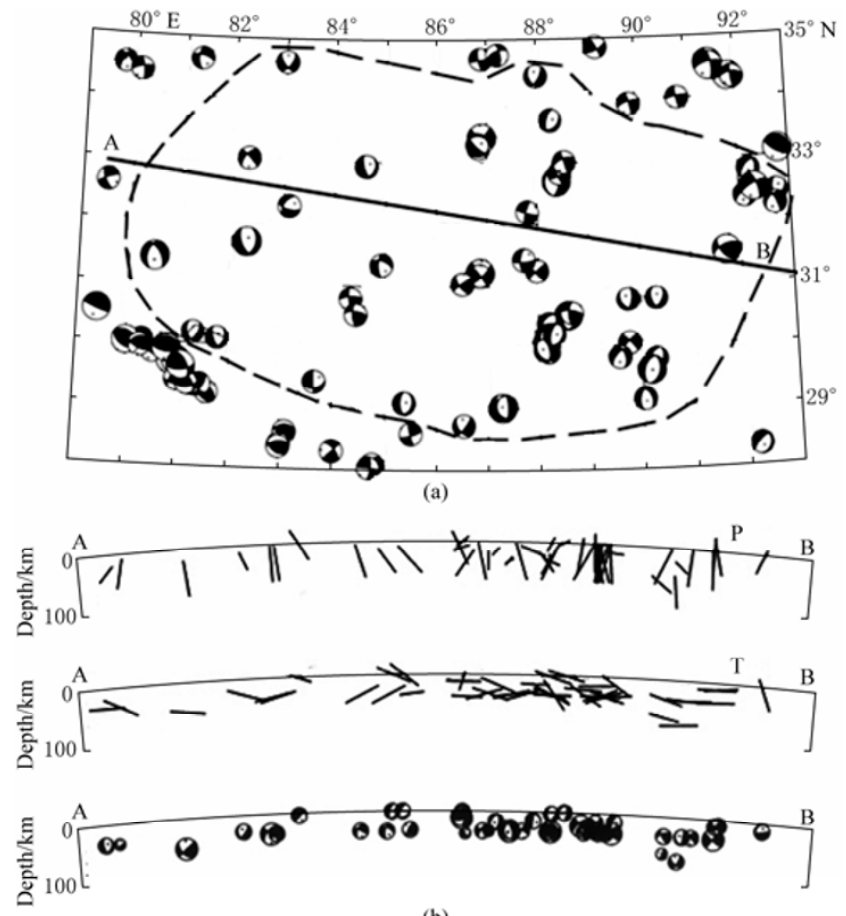

(b)

Figure 5 Equal area projection diagrams of focal mechanism solutions (upper diagram) in the altitude of the plateau (about $28.5^{\circ} \mathrm{N}-34.5^{\circ} \mathrm{N}$ and longitude $80^{\circ} \mathrm{E}-93^{\circ} \mathrm{E}$ )(a). Profiles of the $P-, T$ - axes and equal area projection diagrams along line $A B(\mathrm{~b})$.

Figure 6 shows the statistical charts of azimuths and dips of the compressive $(P)$ and extensional $(T)$ axes in region $A B$ in Figure 5. The extensive stress in the 
nearly E-W direction dominates the seismic fault activities. The characteristics of the tectonic stress field in the regions of high elevation on the Tibetan plateau are clearly different from those in the southern margin of the Himalayan front. The horizontal components of $P$-axes of fault plane solutions in Figure 6 are very little and align likely along the N-S direction on a whole. The components of $T$-axes are great, aligning in the E-W direction.
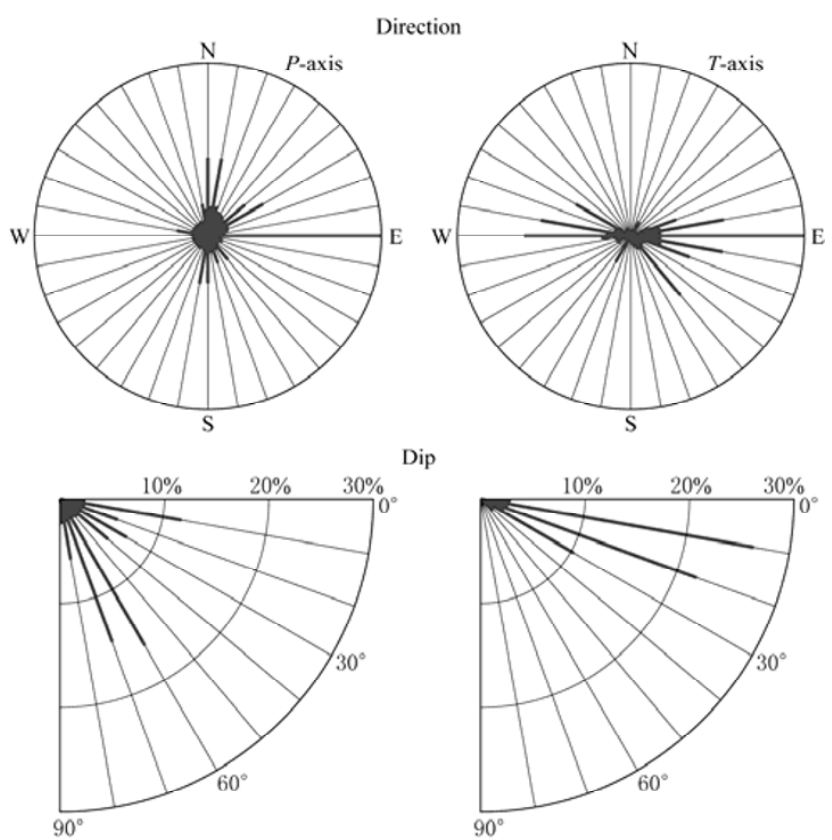

Dip

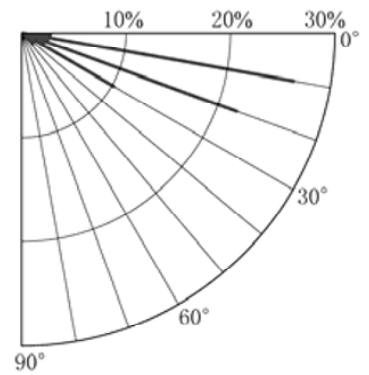

Figure 6 Statistical charts of azimuths and dips of compressive $(P)$ and extensional $(T)$ axes in the southern and central part of the Tibetan plateau in Figure 5.

The upper and lower diagrams of Figure 7 show the equal area projection diagrams for source mechanism solutions in the horizontal surface and those in the profile along $A B$, respectively. It can be seen from Figure 7 that events are normal or strike-slip faulting ones in the region except the July 23, 1972 Naqu $\left(91.7^{\circ} \mathrm{E}\right.$, $\left.31.5^{\circ} \mathrm{N}\right) \mathrm{M6}$ event. Specially, the events in the geothermal anomaly area are almost complete normal faulting events dominated by the extensional stress field near E-W direction. The earthquake faults probably are in $\mathrm{N}-\mathrm{S}$ direction because both of the node planes of focal mechanism solutions for events are all near N-S direction. For example, the $M 5.5$ event $\left(29.81^{\circ} \mathrm{N}, 89.57^{\circ} \mathrm{E}\right.$, depth $=75 \mathrm{~km}$, after Harvard university database) occurring in the September 14, 1976 is a typical normal faulting event that the extensional dislocation in E-W direction riches about several tens centimeters or one meter. It suggests that the seismicity and tectonic motion in the lithosphere are dominated by extensional stress along the E-W direction in the thermal anomaly area.
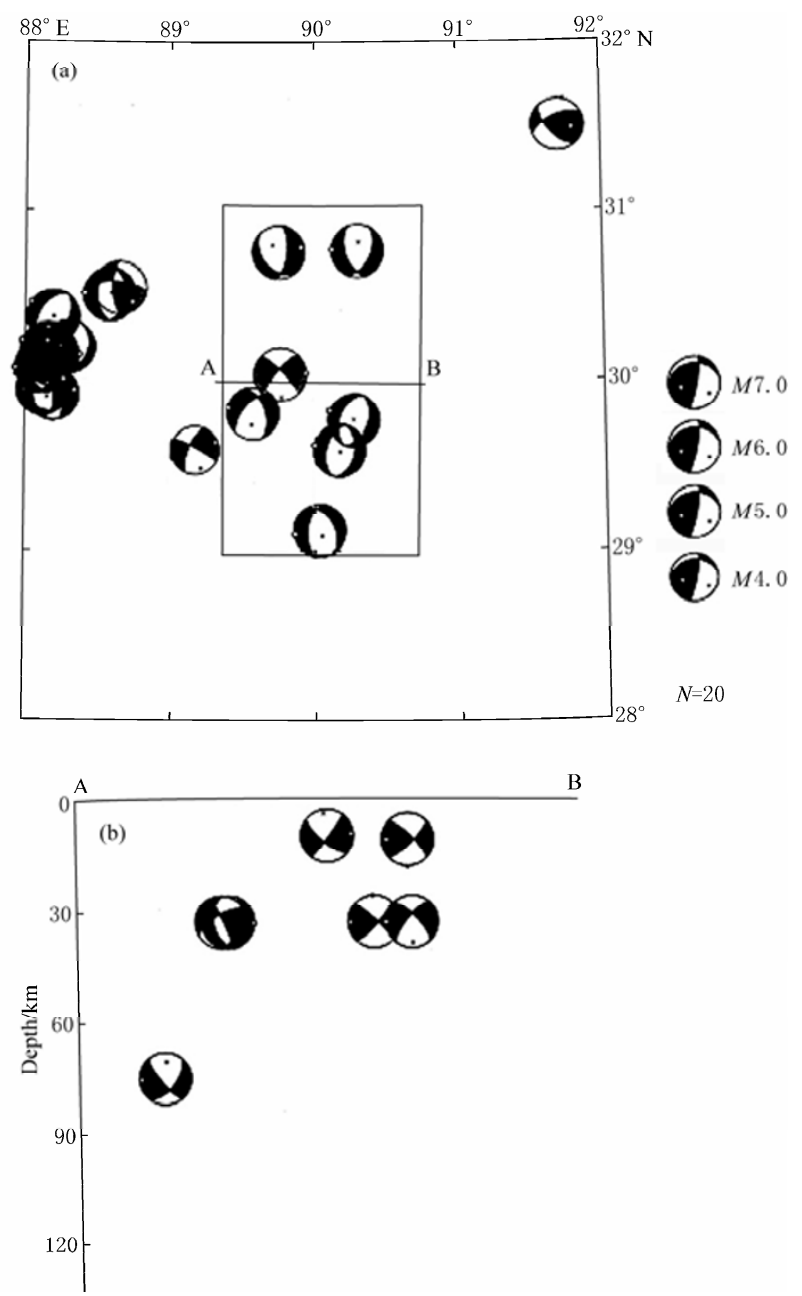

Figure 7 Equal area projection diagrams of lower half-sphere projection for focal mechanism solutions in the horizontal surface (a) and those in the profile along $A B$ (b), respectively.

Such stress field results in the middle and strong M6 normal faulting events to occur frequently and generate dislocations in E-W direction in the geothermal anomaly area. These brittle fractures extend about $110 \mathrm{~km}$, the bottom of lithosphere. A series of brittle fractures in different depths may be a reason of thermal anomaly activity in the plateau.

\section{Discussion and conclusions}

The geothermal anomaly activities and seismotectonics characteristics in the plateau are discussed in the present analysis. A lot of boiling springs and hydrothermal explosions, geysers and boiling fountains align 
along the faulted-depression zone strike in the altitude, central and southern parts of the plateau as mentioned above. Results obtained by the seismo-tectonic analysis show many events of normal faulting type with near N-S direction occur in the thermal anomaly area although the tectonic structures in the plateau mainly reveal the large scale of compressive or compressive-shear faults extending along about the E-W direction (Zhao et al, 1990). The stress extending in the E-W direction dominates the seismicity of normal faulting event extending in E-W direction. The high heat flow anomaly phenomena appear evidently along the splitting valleys likely the N-S direction. The region of anomalously geothermal activity coincides that of the normal faulting type event occurring. The normal faulting earthquakes are mainly tectonic activity regimes in the thermal anomaly region. The strike directions of events are likely the N-S direction, coinciding with the strike of the thermal anomaly active belts. The earthquakes align along the normal faults and faulted-depression zone with the N-S direction. The thermal anomaly activity also distributes along the faulted-depression zone. The events with middle and deep depths occurred beneath the geothermal anomaly activity region in the altitude of the plateau as well as. The hypocenters extend from the crust to the $110 \mathrm{~km}$, near the bottom of the lithosphere. The stress field extending in E-W direction dominates the brittle fractures from the surface to the lithospheric bottom of $110 \mathrm{~km}$ (Shi and Zu), 2003; Zeng et al, 2000). Analyses for such seismotectonic and the thermal activities may inspire the study of dynamics of the plateau movements. The lithosphere extends along the $\mathrm{E}-\mathrm{W}$ direction due to the E-W extensional stress in the central and southern Tibetan plateau. The tensional stress in the $\mathrm{E}-\mathrm{W}$ results in the lithosphere fractures and the normal faults striking $\mathrm{N}-\mathrm{S}$ direction, grabens and faulted-depression zones. The heat flows from the asthenosphere well upward to the surface along the columnar seismic fractures and faults through the thick crust. The thermal anomaly activities may be related to the upwelling heat flow from mantle in the altitude of the Tibetan plateau.

Results of GPS observation show that the crust motion changes the direction from the NE to NNE in the middle and southern region of the Tibetan plateau. The extensional strain ratio is $20 \times 10^{-9} / \mathrm{a}$, which is the greatest one in the Chinese mainland (Yang et al, 2002). Results of resistivity show the thermal lithosphere is about $120 \mathrm{~km}$ in the zone northwest of Lhasa in the south plateau. It may be related to the asthenosphere upwelling.
The greatest minus Bouguer anomaly $(-500--540) \times$ $10^{-5} \mathrm{~m} / \mathrm{s}^{2}$ in the plateau appears in the middle and southern region. The results imply that large scale of fractures might exist in the lithosphere in the thermally active region (Bourjot and Romanowicz, 1992; Zhao et al, 1993). There are probably molten granite layers of low density under high temperature beneath the high thermally anomalous region. These results are consistent with that obtained from the present analysis.

The lithospheric thickness is generally taken as the thermodynamic, mechanic and chemical, three kinds of boundary thickness depending on property for study object (Stein and Stein, 1996). The geothermal gradient increases rapidly with the deep in the central and southern region of the plateau, specially (Teng, 2003). The brittle fracture, or earthquake occurs as the stress in the lithosphere is greater than the stress strength of rock. The rock loss the condition of stress accumulation as the temperature reaches $800^{\circ} \mathrm{C}$ in the deep. The creep may occur with temperature increase in the deep. The hypocenter depth reaches $110 \mathrm{~km}$ as mentioned above suggests that the brittle fractures occur in the lithosphere from the surface to $110 \mathrm{~km}$. Thermal materials from the mantle can well upward to the surface along the extensional faults and fractures. The high heat flow may melt the rock and also result in the partly melted granite in the lithosphere. So the high thermal anomaly is attributable to the extensional stress and earthquake activity in the altitude region of the plateau. The geothermal activities in the altitude of the plateau began at the uplift of the Tibetan plateau $150 \mathrm{ka}$ ago and last to now (Han, 1990). The block of the plateau undergoes the uplifting-extending-hydrothermal explosion and boiling fountain in time series (Stein and Stein, 1996). The thermal activity is also one characteristic of deutero-orogeny in the collision zone.

The compression stress field due to the collision between the Indian and Eurasian plates results in the uplift of the Tibetan plateau. So it is easy to understand the compressive stress activities in the surrounding edges of the plateau. The results in the present analysis, however, show the extensional stress appears in the thermal anomaly area in the center and southern regions of the plateau, the stress is released by normal faulting earthquake activity. It is necessary for the study of geodynamics to investigate the extensional stress field and tectonic motions in the central and southern regions of the plateau with $4000 \mathrm{~m}$ altitude. The lithosphere structure is obviously heterogeneous in the Tibetan plateau. 
The accurate seismic observations and study on lithosphere structure will benefit clarification of the mechanism of thermodynamics and geodynamics in the plateau.

Acknowledgements This study was supported partly by National Natural Science Foundation of China (No.40674026), Commonweal Special Science Foundation of China (No. 200811037) and Geological Survey Foundation of Ministry of Land and Resource, China (No.1212010916083). The authors express the thanks to the three reviewers for their valuable comments.

\section{References}

Bourjot L and Romanowicz B (1992). Crust and upper mantle tomography in Tibet using surface waves. Geophys Res Lett 19: 881-884.

Brown E T, Bendick R, Bourles L D, Faur V, Molnar P, Raibeck M and Yiou F (2002). Slip rates of the Karakorum fault, Ladakh, India, determined using cosmic ray exposure dating of debris flows and moraines. $J$ Geophys Res 107 (B9): 2 192, doi:10.1029/2000JB000100.

$\mathrm{Fu} \mathrm{Z,} \mathrm{Xu} \mathrm{J} \mathrm{and} \mathrm{Huang} \mathrm{J} \mathrm{(2000).} \mathrm{Numerical} \mathrm{simulation} \mathrm{of} \mathrm{the} \mathrm{compression}$ uplift of the Qing-Zang plateau. Chinese J Geophys 43: 346-355 (in Chinese with English abstract).

Han T (1990). Relationship of the Active Structural System to Geothermal Activity in Southern Xizang (Tibet), in Himalayan Geology. Geological Publishing House, Beijing, 45-58 (in Chinese).

Housemen G A and Mckenzic D P (1981). Convective instability of a thickened boundary layer and its relevance for the thermal evolution of continental convergence belt. J Geophys Res 86: 6115-6 132.

Molnar P, England P and Martinod J (1993). Mantle dynamics, the uplift of the Tibetan Plateau, and the Indian monsoon. Rev Geophys 31: 357-396.

Qin C, Papazachos C and Papadimitriou E (2002). Velocity field for crustal deformation in China derived from seismic moment tensor summation of earthquakes. Tectonophysics 359: 29-46.

Robert S, Yeats K S and Clarence R A (1997). The Geology of Earthquakes. Oxford University Press, New York, 256-257.

Shen X J, Zhang W R and Guan Y (1989). Heat flow transect along Yadong-Qaidam through Tibetan Plateau. Chin Sci Bull 34(17): 1 3191330 .

Shi Y L and Zu S B (2003). Contrast of rheology in the crust and mantle near Moho revealed by depth variation of earthquake mechanism in continental China. Chinese J Geophys 46(3): 359-365 (in Chinese with English abstract).
Stein S and Stein C A (1996) Thermo-mechanical evolution of oceanic lithosphere: Implication for the subduction process and deep earthquakes. Subduction top to bottom. In: Gray E B, David W S 1, Stephen H K and John P P eds. AGU Press, Washington, 1-17.

Teng J W (2003). Outline of Solid Geophysics. Seismological Press, Beijing, $174-183$.

Wang Y and Xu H (2003). Convergence rate of the India plate to Eurasia subduction beneath Qing-Zang plateau-Inversion result from the GPS observed data. Chinese J Geophys 46: 185-190.

Wei D, Zhang M T and Zhang Z F (1981). Geothermal In Tibetan. Science Press, Beijing, 27-36.

Xu J R (1994). Seismogenic Stress field and tectonics in East Asia. Memoirs of the Faculty of Kyoto University (Series of Physics, Astrophysics, Geophysics and Chemistry) XXXIX(1): 49-69.

$\mathrm{Xu} \mathrm{J} \mathrm{R}$ and Kono Y (2002). Geometry of slab, intraslab stress field and its tectonic implication in the Nankai Trough, Japan. Earth Planet Space 54: $733-742$.

Xu J R, Zhao Z X and Ishikawa Y (2008). Regional characteristics of crustal stress field and tectonic motions in and around Chinese mainland. Chinese J Geophys 51(3): 861-869 (in Chinese with English abstract).

Xu J R, Zhao Z X, Ishikawa Y and Oike K (1988). Properties of the stress field in and around West China derived from earthquake mechanism solutions. Bull Disas Prev Res Inst, Kyoto Univ 38 Part 2 (333): 49-78.

Xu J R, Zhao Z X, Kono Y and Kinoshita H (2003). Regional characteristics of stress field and its dynamics in and around the Nankai trough, Japan. Chinese J Geophys 46: 488-494 (in Chinese with English abstract).

$\mathrm{Xu}$ Z H (2001). Modern tectonic stress in East Asia. Acta Seismologica Sinica 23(5): 492-501 (in Chinese with English abstract).

Yang G H, Li Y X, Han Y P, Hu X K and Gong Y M (2002). Current horizontal strain field in Chinese mainland derived from GPS data. Acta Seismologica Sinica 24: 338-347 (in Chinese with English abstract).

Zeng Z, Ding, Z and Wu Q (2000). Seismological evidence for the mulitiple incomplete crustal subductions in Himalaya and south Tibet. Chinese $J$ Geophys 43: 780-797.

Zhang Y (2000). Three dimension upper mantle structure beneath East Asia and its tectonic implication. In: Martin E J F, Sun-Lin Chung, Ching-Hua Lo and Tung-Yi Lee eds. Mantle Dynamics and Plate Interaction in East Asia. AGU, Washington, 11-23.

Zhao W, Nelson K D and Project INDEPTH Team (1993). Deep seismic reflection evidence for continental underthrusting beneath southern Tibet. Nature 366: 557-559.

Zhao Z X, Matsumura K, Oike K and Ishikawa Y (1988). Regional characteristics of temporal variations of seismic activity in east Asia and their mutual relations (3) West China and its neighboring regions. Zisin 41: 389-400.

Zhao Z X, Oike K, Matsumura K and Ishikawa Y (1990). Stress field in the continental part of China derived from temporal variations of seismic activity. Tectonophysics 178: 357-372. 